\author{
Т.А. Свиридченкова
}

\title{
ЭМОЦИИ И ЦВЕТНЫЕ ОБРАЗЫ В ДЕТСКИХ СНОВИДЕНИЯХ
}

\begin{abstract}
Аннотация. Предметом исследования является взаимосвязь эмоциональных состояний (страх, тревога, удовольствие, удовлетворение) во сне, основных функций сновидения (защитной, компенсаторной и адаптивной) и вторичных образов, представленных определённым иветом в детских сновидениях. Объектом исследования являются дети в возрасте от пяти до семи лет. Автор подробно рассматривает такие темы как влияние ивета на психическое, психологическое и физиологическое состояние человека; сновидение и его функции; образы сновидения как вторичные образы, сигнализирующие о наличии невротического состояния. Особое внимание уделяется появлению в детских сновидениях того или иного цветного образа, его взаимосвязи с эмоциональным состоянием сновидиа, работой сновидения и наличием психологической проблемы. В исследовании использовались методы опроса, анализа, сравнения. Для определения и подтверждения статистически значимых различий между появлением в страшных и приятных сновидениях того или иного цвета использовался Т-критерий Стьюдента.

Полученные результаты эмпирического исследования показали, что существует взаимосвязь эмоциональных состояний (страх, тревога, удовлетворение, удовольствие) во сне и вторичных образов в сновидениях, представленных определённым иветом. Выделены доминирующие иветные образы, характерные для страшных детских сновидений и цветные образы, характерные для детских сновидений с приятным сюжетом. Результаты исследования могут быть использованы в рамках ранней диагностики и профилактики невротических состояний, которые ещё не проявились в виде клинических симптомов заболевания в бодрствующем состоянии, но уже появляются в сновидных образах, представленных определённым цветом.

Ключевые слова: детское сновидение, функции сновидения, вторичный образ, невротическое состояние, эмоции, страх, тревога, удовлетворение, удовольствие, цветной образ.

Abstract. The subject of the research is the relationship between emotional states (fear, anxiety, pleasure, satisfaction) experienced while dreaming, the main functions of dreams (protection, compensation and adaptation) and secondary images presented as a certain color in baby dreams. The object of the research is children from five to seven years old. The author of the article examines such topics as the impact of color on mental, psychological and physiological states of human; dreaming and its functions; dreamed images as the secondary images indicating neurotic condition. Special attention is paid to a particular color image appearing in children's dreams, relation of this color image to the dreamer's emotional state and color image as a sign of a psychological problem. In her research Sviridchenkova has used such research methods as survey, analysis and comparison. To define and validate statistically significant differences between appearances of a particular color in scary and pleasant dreams the researcher has used the Student's t-criterion. The results of the research demonstrate that there is a relationship between emotional states (fear, anxiety, pleasure, satisfaction) experienced by a dreamer and secondary images presented by a particular color in dreams. The researcher describes the dominating color images typical for scary children's dreams and color images typical for pleasant dreams seen by a child. The results of the research can be used for early diagnostics and prevention of neurotic states that haven't formed clinical symptoms yet but can be already found in dreams as color images of a particular color.
\end{abstract}

Key words: gratification, anxiety, fear, emotions, neurotic state, secondary image, dreaming function, children's dreams, pleasure, color image.

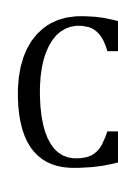

новидения с древних времён являются областью познания философии, психологии и физиологии. Сновидения - это главный ключ к разгадке сознания и психики человека. В данной работе содержание сновидений рассматриваются как вторичные образы.
Изучением образной сферы человека учёные занимались с античных времён. Реальностью считались «образы-эйдосы» у греков. Люди верили, что с помощью фантазийных, воображаемых и сновидных образов - представлений «божественный мир» общался с душой. Научным периодом изуче- 


\section{Психология и психотехника 3(90) • 2016}

ния образной сферы можно считать XIX в. (Гальтон, Пуркинье, Вундт, Фехтнер, П. Макеллар). Отечественные учёные во второй половине XX в. изучали вторичные образы в рамках общей психологии (Б.Г. Ананьев, С.Л. Рубинштейн, А.Н. Леонтьев, Б.Ф. Ломов, Б.М. Теплов, Л.М. Веккер, Ф.Н. Шемякин и др.), педагогической и возрастной психологии (И.С. Якиманская, Е.Н. Кабанова-Меллер и др.), психологии труда и инженерной психологии (Б.Ф. Ломов, Д.Н. Завалишина, В.А. Пономаренко, Н.Д. Завалова) [5].

Вторичные образы в широком понимании это образы предметов и явлений, появляющиеся в субъективном мире человека в отсутствие непосредственно воздействующего на них стимула прообраза [2].

Вторичные образы выполняют множество функций. Одной из главных функций является эмоционально-экспрессивная функция, отвечающая за сохранение в виде образов аффективный (осознанный и неосознанный) опыт, который влияет на возникновение эмоциональных реакций (переживания снов и фантазий, где возможно реализовать то, что недопустимо в реальности). Так же вторичные образы широко раскрывают внутренний мир личности, так как являются обладателями и распространителями знаково - символической репрезентации [5].

К вторичным образам относятся: репродуктивные образы памяти (оперативной, кратковременной, долговременной), образы - представления о предметах и явлениях окружающего мира, образы воображения, фантазийные образы, образы изменённых состояний сознания. К вторичным образам можно отнести и образы сновидений.

В работе образной сферы участвует вся психика, следовательно, содержание вторичных образов безгранично (образы изменённых состояний сознания, сновидения), и в качестве объясняющих символов используются образы, которые определяются индивидуальными характеристиками самого человека. Так как вторичные образы являются самым простым языком психики, связанным с допонятийным уровнем отражения, они предоставляют возможность проникать в самые глубокие слои психики, куда нет прохода рациональному познанию.

Сновидение - это целостная, многоуровневая, многомерная, многофункциональная система психических и физиологических актов в работе индивидуальной психики и сознания; это состояние, процесс, пространство, психологический механизм, который в образах и символах отражает субъективную реальность сновидца [6; 7; 9].
В настоящее время выделяют несколько подходов в изучении сна и сновидений:

- физиологический (естественнонаучный) Ю. Азеринский, М. Жюве, Н. Клейтман, Ф. Крик, Р. Маккарли, В.С. Ротенберг, Э. Хартманн, Г. Нудов, И.П. Павлов, И.М. Сеченов, Л.А. Орбели, В.Н. Касаткин, С.В. Авакумов, Е.А. Корабельникова, В.Л. Голубев, А.Л. Южанинова, О.В. Красноперов, А.Л. Панченко;

- психологический 3. Фрейд, Дж. Салливан, Л. Саул, О.Фенихель, Ш. Ференци, Х. Сегал, Р.Д. Столороу, Р. Гринберг, С. Перлман, Д. Спаньярд, Дж. Тэйлор, Дж. Холл, К. Юнг, А. Адлер, Г. Мосак, С. Гингер, Ф. Пёрлз, Э. Фромм, Г. Лейтц, Я. Морено, Л. Бинсвангер, М. Босс, Дж. Бьюдженталь, Т. Грининг, Р. Мэй, И. Ялом, А. Минделл;

- трансперсональный (эзотерический) Р. Боснак, П. Гарфилд, С. Гроф, Джонсон, Дж. Диллард, С.К. Кастанеда, С. Лаберж, Т. Маккенна, М. Мерфи.

Изучение сновидений в основном связано с естественнонаучным подходом, поэтому очень важное научное значение представляет менее разработанный психологический подход [11].

Основоположником теории толкования сновидений является Зигмунд Фрейд - знаменитый психоаналитик, выдвинувший и обосновавший теорию о том, что во сне человек погружается во внутреннюю реальность, в своё собственное бессознательное. 3. Фрейд считал сновидения неким патологическим феноменом - проявлением вытесненных из сознания в бессознательное, инфантильных желаний. Это желания, которые в силу возраста, не могли быть исполнены (речь идёт в основном о сексуальных желаниях) и осознаны. Не справившееся с ними детское Эго вытеснило их из сознания. Во время сна линия вытеснения слабеет и желания Ид стремятся к исполнению в галлюцинаторной форме. Не полностью отключенная во сне, критикующая инстанция (цензура) искажает и маскирует форму исполнения инфантильного желания. Кроме этого, образы сновидений подвергаются работе сновидения: сгущению, смещению, изобразительной деятельности, символизации (как функции цензуры), что делает сновидение мало похожим на реальность. Именно запрёт на прямое исполнение запрещённого желания запускает механизм цензуры и символизации. Затем сновидение подвергается вторичной обработке и становится более целостным и логичным.

Один из механизмов работы сновидения превращение мыслей в зрительные образы. Язык символов - это такой язык, с помощью которого 
внутренние переживания, чувства и мысли, в виде определённых образов приобретают форму явственно осязаемых событий внешнего мира.

Во сне человек погружается в мир своих глубинных переживаний, страхов, фантазий и желаний, которые воплощены в символических образах. Сновидение должно представить наглядное изображение слова, абстрактные понятия. Задача сновидения - показать в картинах сложные чувства. Но чувство сложно представить простой картинкой и поэтому сновидение изображает действие, обозначающее это чувство. Так же для отражения в сновидении того или иного чувства, возможно появляется и определённый цветной образ. Таким образом, образ (символ) - это результат бессознательной проекции определённого внутреннего психического состояния или душевного переживания на воображаемый внешний стимул. Такими образами - символами могут выступать разные предметы, люди, животные, механизмы, пейзажи (город или природа), действия и т.д. Существуют так же и физиологические характеристики сновидений. К ним можно отнести: частоту сновидений, субъективную активность засыпания, информативность, эмоциональность сновидений, повтор сновидений, наличие в сновидениях речи, яркость, контрастность, звуки, обонятельные, вкусовые и тактильные ощущения, восприятие цветных образов и т.д.

У каждого сновидца эти характеристики и образы сугубо индивидуальны, в зависимости от особенностей личности, переживаемых эмоций и влияния внешних факторов. Спящий является «режиссёром» своего сновидения.

Существенное влияние на характеристики сновидений оказывают особенности личности. С античных времён известно, что сновидения могут нести информацию о заболеваниях человека. Сновидения как вид психической активности отражает все изменения, которые происходят в жизнедеятельности человека. Некоторые исследователи, обращают внимание на тот факт, что частота сновидений и их содержание зависит от адаптивных, психотипологических особенностей личности.

Структура и содержание сновидений высокотревожных, больных тем или иным видом невроза, людей значительно изменяются по сравнению со сновидениями здорового человека. Мозг невротиков очень чувствителен к малейшим изменениям, происходящим в организме человека. Те события и состояния, что у здорового человека могут практически никак не отразиться в сновидениях, у больных неврозом производят значительные изменения [7]. Анализом проявления патологических процессов во сне (до манифестации симптома) занимались наши соотечественники В.Н. Касаткин, В.М. Блейхер, С.Н. Боков, О.В. Красноперова, Е.А. Корабельникова, В.И. Лыков, А.Е. Архангельский и др.

В.Н. Касаткин, изучая диагностику болезней по сновидениям, обратил внимание, что даже при лёгком функциональном нарушении, которое не замечается человеком в бодрствующем, сознательном состоянии, образы сновидения претерпевают изменения. В сновидениях невротиков часто воспроизводятся фрустрирующие ситуации, которые играли главную, решающую роль в возникновении невроза.

Элементы сновидений - это проекции определённых аспектов личности человека и непосредственно воспринимаемой им реальности, в том числе и тех, которые отвергаются и не признаются бодрствующим сознанием. Следовательно, наши сновидения дают нам наиболее полную картину нашей многогранной личности и чутко улавливают малейшее проявление неблагополучия в состоянии здоровья или психики, изменяя при этом характер образных характеристик (цвета, чувства, эмоции). Сновидение выполняет множество функций. Адаптивная, компенсаторная и защитная функции являются главными и обеспечивают психологическую защиту, эмоциональную разрядку и адаптацию организма сновидца [10].

Особенным феноменом является детское сновидение, так как в меньшей степени подвержено искажению и тем самым даёт более лёгкую возможность интерпретации. Своё внимание на изучение детских сновидений обращали 3. Фрейд, А. Фрейд, Юнг, Адлер, Фромм, Бёрн, Пёрлз и многие другие великие учёные. В последнее время огромное количество учёных по всему миру всерьёз заинтересовалось изучением детских сновидений. Отличие детского сновидения от взрослого состоит в том, что малыш видит всё в упрощённом виде. Эмоциональные переживания ребёнка (радость, страх, злость), не нашедшие в течение дня, условий для проявления вытесняются. Поэтому в сновидениях эмоции персонажей похожи на вытесненные эмоции ребёнка, сновидение как бы «компенсирует недостачу» в эмоциональной жизни. У взрослых в сновидении всё завуалировано, истинные чувства и эмоции сильнее видоизменены. Детское сновидение практически открыто, без выраженных искажений, показывает реакцию на событие, которое оставило обиду, гнев, неисполненное желание. Если даже содержание детских сновидений усложняется и утончается, всё-таки в них легко увидеть фрустрированное желание. Детские сновидения являются наиболее простыми, примитивными, 


\section{Психология и психотехника 3(90) • 2016}

архаичными, схематичными и более прямыми по смыслу. У ребёнка ещё нет длительного опыта, не накоплены жизненные ситуации, которыми бы «сновидящее Эго» могло бы оперировать в общем сюжете сна. В сновидении ребёнка происходит практически прямое, незамаскированное работой сновидения, исполнение запретного желания.

Объектом переработки в сновидении является не просто информация, а активированные ею неприемлемые мотивы и установки. Устраняется же этот конфликт не логическим путём, а с помощью языка образов. Образное мышление является доминирующим в возрасте 4-7 лет. Оно представляет собой особый вид мыслительного процесса, осуществляемый непосредственно при восприятии окружающей действительности, а необходимые образы хранятся в кратковременной и оперативной памяти. Манипулируя в уме с образами, ребёнок представляет себе реальное действие и его результат, позволяя наметить выполнения конкретной задачи в той или иной ситуации. В сновидении образное мышление обеспечивает как бы временную совместимость несовместимых установок, устраняет антагонизм между ними.

В этом же возрасте постепенно усложняется эмоционально - чувственная сфера: ребёнок различает не только радость или страх, но и удивление, ревность, жалость, гнев, нежность, застенчивость, грусть, удовольствие, бодрость и т.д. Дети уже пытаются управлять своими желаниями и эмоциями, осваивая социальные нормы. Детские переживания, эмоции и чувства приобретают более продуманный и произвольный характер, а значит приходит время для таких процессов как вытеснение и тревога.

Во время сновидения в образной форме идёт постоянный поиск путей примирения конфликтных установок и по ходу поиска происходит частичное или полное достижение искомого. После такой переработки отпадает необходимость в вытеснении, исчезает тревога. В результате преобладания образного мышления и сюжеты сновидения у детей более простые и понятные.

В дошкольном возрасте (от 4 до 7 лет), в результате социализации, формируется Суперэго структурная составляющая личности. Оно образовывается в результате поощрения или наказания значимыми лицами за определённое поведение и стремление ребёнка. Именно в этот период закладывается и начинает развиваться совесть, которая обладает свойством наказывать «изнутри», порождая при этом чувство вины. В процессе идентификации с родителями и другими значимыми лицами происходит формирование идеального Я. Суперэ- го оценивает, что и насколько соответствует принятым в обществе нормам морали, требованиям и запретам и становится действующим внутренним источником наказаний. Ребёнок испытывает психологические мучения за неспособность соответствовать стандартам идеального Я. 3.Фрейд и А.Фрейд отмечали, что особенности страха в старшем дошкольном возрасте связаны именно с формированием Суперэго. Я ребёнка испытывает сильнейшую тревогу, которую инициируют силы инстинктов Ид, объективная тревога (страх возможности наказания со стороны внешних сил), а теперь ещё и формирующееся Суперэго. Возникает опасность того, что личностная организация Я может быть разрушена или затоплена. И тогда на помощь приходит сновидение, которое выступает как защитный механизм. В сновидении отвергнутые инстинктивные импульсы стараются прорваться обратно в сознание и в фантазийной, образной форме получают возможность «договориться» с Я и Сверх-Я на лучшей основе и нейтрализовать конфликт. От того насколько полно разрешиться внутриличностный конфликт в сновидении зависит станет ли этот конфликт началом невротического состояния. Таким образом, детские сновидения не бессмысленны: это понятные, полноценные душевные акты. Правильное отношение к сновидениям может иметь большое значение для здоровья и развития ребёнка.

Сновидение является своеобразным индикатором состояния человека, показывает даже самое незначительное проявление какого-либо неблагополучия в состоянии здоровья или психологической проблемы. Анализируя сновидения можно ещё до симптоматического проявления болезни предположить её развитие. Сновидение является невротическим симптомом, который имеет для нас неоценимое преимущество в том, что проявляется у всех здоровых людей, говорил 3. Фрейд [13].

Большой интерес вызывает представленность того или иного цвета в сновидении и его влияние на психические и физиологические процессы во сне.

Цвет - одно из самых загадочных явлений. Даже во сне, с закрытыми глазами мы не перестаём видеть цвета. Цвет является источником многих парадоксов мышления. Цвет - один из достаточно сильных методов информационного, эмоционального и эстетического влияния. С истоков культуры человек стремился овладеть способностью цвета влиять на душевное состояние и использовал цвет в целях создания удобной среды обитания и искусственного воссоздания реальности в изображениях.

С далеких времён людей интересовало влияние цвета на психическую деятельность челове- 
ка, объективация посредством цвета психических процессов и состояний, цветовая психодиагностика и т.д. Формирование зрительного восприятия связано с тремя основными процессами: излучение света - физический этап (преобразование энергии видимого излучения в энергию изменённого потока излучения); физиологический этап (в сетчатке глаза энергия излучения преобразуется в информацию, которая передаётся в головной мозг) и психологический этап, относящийся к высшей нервной деятельности. В результате логической обработки информации всех органов чувств и памяти, ощущение цвета переходит в восприятие. Восприятие цвета определяется индивидуальностью человека [1].

Научные исследования восприятия цвета относятся к началу XX в., к теории трёх основных цветов Юнга - Гельмгольца, к работам Хартриджа, касающихся многоцветного восприятия. Изучением цвета как взаимосвязанного психологического и физиологического процесса, имеющим диагностическое значение занимались такие исследователи, психологи и врачи как Ю.Ф. Поляков, А.М. Иваницкий, Х. Клар, К. Флиннхауз, М. Люшер, А.М. Эткинд, Е.Ф. Бажин, Н.В. Агазаде, А.И. Юрьев и многие другие [12].

Особенности воздействия цветов зависят от объективных свойств самих цветов (чистоты, светлоты, яркости), от свойств воспринимающего человека (национального фактора (раса, этническая группа), культурных традиций, классовых принадлежностей) и его индивидуальных особенностей: возраст, пол, культурный уровень, образование, род деятельности, особенности нервно-психического склада, опыт, память, ассоциативный характер мышления субъекта [3]. Цвет вызывает определённые и специфические изменения в психическом мире человека, интерпретация впечатлений от определённого цвета порождает цветовые ассоциации и образы. Цвет оказывает очевидное воздействие на психологическое, психическое, физиологическое состояние и поведенческие реакции человека и цветные образы являются элементом информации внутреннего и внешнего мира, поэтому интерпретацию цветного образа можно использовать как ключ к толкованию сновидений.

Важную роль в «ночной жизни» человека играют цветные образы, они позволяют глубже узнать оттенки реальной жизни сновидца. Существует много разных теорий о присутствии цвета в сновидении. Некоторые считают, что лишь одно сновидение из трёх может быть цветным, все остальные чёрно-белыми (К. Холл); другие утверждают, что, просыпаясь, человек просто забывает о наличии красок в сновидении (Г. Майер); существует теория, что цвет во сне появляется только при отсутствии психологического конфликта (О.Хаксли); другие же напротив считают появление цвета в сновидении сигналом существующего психологического конфликта и наличие или предрасположенность к различным заболеваниям; существует версия, что цвет во сне появляется при наличии определённого таланта (художественного, артистического и т.д.) [9].

В настоящее время работы, исследующие взаимовлияние определённых психологических состояний и восприятие определённых цветных образов, в основном касаются физиологических параметров и исследуются в состоянии бодрствования. Взаимосвязь же эмоциональных состояний (страх, тревога, удовольствие) во сне и основных функций сновидения (защитной, компенсаторной и адаптивной) с такими характеристиками, как появляющиеся в сновидениях образы того или иного цвета изучены недостаточно. При этом изучение взаимосвязи появляющихся определённых цветовых характеристик в сновидениях, с различными эмоциональными состояниями и защитными функциями сновидения имеет существенное значение для изучения наличия и степени интенсивности внутриличностного конфликта и ранней диагностики неврозов.

Учитывая вышеизложенное, целью настоящей работы явилось изучение взаимосвязи эмоциональных состояний (страх, тревога, удовлетворение, удовольствие) во сне и вторичных образов, представленных определённым цветом и осуществляющих защитную, компенсаторную и адаптивную функции сновидения в детских снах.

В исследовании использовались следующие методы:

- для изучения содержания характеристик вторичных образов сновидений ребёнку предлагалось вспомнить самое страшное и самое приятное сновидение, рассказать их и назвать основные (больше всего запомнившиеся) цвета, которые присутствовали в этих сновидениях.

Исследования проводились на воспитанниках старших и подготовительных групп детского сада № 792 г. Москвы в возрасте от 5-7 лет. Всего было исследовано 73 ребёнка (34 девочки и 39 мальчиков).

Для статистической обработки данных был использован сравнительный анализ t-критерий Стьюдента [4]. Исследовались связи между представленностью определённых цветных образов в сновидениях со страшным и приятным сюжетом. 


\section{Психология и психотехника 3(90) • 2016}

\section{Результаты и их обсуждение}

Всего было исследовано 73 ребёнка (34 девочки и 39 мальчиков). Вспомнить и рассказать сновидения смогли 69 детей (33 девочки и 36 мальчиков), из них приятные сновидения вспомнили 69 детей (33 девочки и 36 мальчиков) и страшные сновидения вспомнили 65 детей (30 девочек и 35 мальчиков).

Исследуя сновидения 73 детей в возрасте от 5 до 7 лет выяснилось, что четверо детей $(5,5 \%)$ не помнят никаких сновидений, практически все дети могут вспомнить приятные сновидения $(94,5 \%)$ и у большинства детей этого возраста бывают страшные сны (89\%), в которых им угрожает смертельная опасность.

В рассказанных сновидениях присутствовали следующие цвета: чёрный, коричневый, белый, красный, сиреневый, серый, синий, оранжевый, зелёный, фиолетовый, жёлтый, розовый, голубой.

Полученные данные показали существование взаимосвязей между представленностью определённых цветных образов в сновидениях со страшным и приятным сюжетом.

При сравнительном анализе (t-критерий Стьюдента) были выявлены достоверно значимые различия между появлением в страшных и приятных сновидениях:

- $\quad$ чёрного цвета ( $\mathrm{tKp}=22,3 ; \mathrm{p} \leq 0,05 ;$ эмпирическое значение находится в зоне значимости),

- $\quad$ красного цвета ( $\mathrm{tKp}=5,5 ; \mathrm{p} \leq 0,05$; эмпирическое значение находится в зоне значимости);

- синего цвета (tKp=5,3; $\mathrm{p} \leq 0,05$; эмпирическое значение находится в зоне значимости).

Эти показания говорят о том, что в страшных сновидениях образы чёрного, красного и синего цвета появляются намного чаще, чем в сновидениях с приятным сюжетом.

При сравнительном анализе (t-критерий Стьюдента) были выявлены достоверно значимые различия между появлением в приятных и страшных сновидениях:

- жёлтого цвета (tKp=10,5; $\mathrm{p} \leq 0,05$; эмпирическое значение находится в зоне значимости),

- $\quad$ розового цвета ( $\mathrm{tKp}=8,2 ; \mathrm{p} \leq 0,05 ;$ эмпирическое значение находится в зоне значимости),

- голубого цвета ( $\mathrm{tKp}=7,9 ; \mathrm{p} \leq 0,05$; эмпирическое значение находится в зоне значимости),

- $\quad$ зелёного цвета ( $\mathrm{tKp}=6,7 ; \mathrm{p} \leq 0,05$; эмпирическое значение находится в зоне значимости),

- оранжевого цвета (tKp=5,1; $\mathrm{p} \leq 0,05$; эмпирическое значение находится в зоне значимости).

Эти показания говорят о том, что в приятных сновидениях образы жёлтого цвета, розового цве- та, голубого цвета, зелёного цвета и оранжевого цвета появляются чаще, чем в сновидениях со страшным сюжетом.

Причины этих взаимосвязей можно объяснить с позиций как психологических, так и физиологических теорий.

Чёрный цвет на физиологию человека действует практически автоматически: вызывает резкое понижение настроения, является мрачным, тяжёлым, угнетающим цветом. Символическое значение чёрного цвета - это темнота, страх, смерть, разрушительность, подавление, неясность, депрессия, пустота. Чёрный цвет воздействует как нечто без возможностей, как нечто неживое, как тишина без будущего. Чёрный цвет бросает вызов, человек должен пройти через пугающую неизвестность, чтобы познать себя [3; 12].

Красный цвет является активным, является навязчивым, принуждает к действию, возбуждает нервную систему, вызывает учащение дыхания, пульса, активизирует работу мускульной системы, как при любом волнении. Ненадолго повышает работоспособность, после чего организм утомляется, снижается внимание и реакция. Красный является цветом экстраверсии, цветом импульса, обращённого наружу. Красный цвет тёплый, воздействует внутренне как подвижный, живой, беспокойный цвет. Красный цвет символизирует агрессию, физическую силу, мужество, сексуальность, чувственную любовь, опасность, храбрость, бодрость, здоровье, жизнерадостность. Во время сновидения яркий красный цвет символизирует открытый гнев, а тусклый красный показывает, что гнев подавляется. Красный - знак прямых и активных действий. Он связан с волей и властью. Во сне он может необычайно взбодрить и помочь справиться с медлительностью, депрессией и меланхолией. Красный цвет в сновидении способен помочь справиться со страхом и нерешительностью. Это цвет «действия», цвет «выполнения работы» [3; 12].

Синий цвет оказывает тормозящее, успокаивающее действие на нервную систему, при его воздействии снижается активность жизненных процессов, нормализуется дыхание и пульс, так как он считается пассивным, спокойным, холодным, способствует затормаживанию функций физиологических систем человека. Группа синего для пассивной интроверсии и импульсов, обращённых внутрь. Синий цвет вызывает состояние созерцательности и размышления. Синее развивает центростремительное движение (подобно стягивающей себя в свой домик улитке) и удаляется от человека. В синем глаз утопает. Синее склонно к углублению. Синий цвет - это постоянство, упор- 
ство, настойчивость, преданность, самоотверженность, серьёзность, строгость. Очень тёмное синее даёт элемент покоя [3; 12$]$.

Возможно эти же свойства цветов использует психика, чтобы обеспечить защитную и адаптивную функции сновидения. Сновидение старается, не дав постыдной или устрашающей природе желаний Ид разбудить сновидца, сохранить сон. Когда Эго спит, вытесняющая сила ослабевает, и напряжения Ид находят лазейки. Даже в спящем состоянии возмущённое и карающее Супер-Эго разбудило бы сновидца, если бы ему стали понятны истинные цели и желания Ид. Если напряжение Ид становится настолько сильным и откровенным, несмотря на Суперэго и ослабленную силу вытеснения, что сохраняется и во сне, Эго начинает пробуждаться. Начинается страшная борьба между Эго, Супер-Эго и Ид, призванная не допустить открытого проявления Ид. Если Эго не справляется, человек в ужасе просыпается - что и является одним из проявлений невротического состояния [14].

В страшных сновидениях чёрный цвет может символизировать состояние тревоги, страха, угнетающей неизвестности и смертельной опасности (действие Супер-Эго на прорывающееся неудовлетворённое желание Ид). Чтобы справиться со страхом, снизить уровень тревоги и продолжить сон (работа защитной функции сновидения) появляется красный цвет, который активизирует все психические и физиологические процессы, позволяя сновидящему почувствовать храбрость, мужество, силу и начать действовать (борьба между Ид и Супер-Эго). С другой стороны, красный цвет так же может символизировать само желание Ид животное начало, агрессия, сексуальные и инстинктивные желания, не подчиняющиеся никаким моральным принципам. Синий же цвет выступает как стабилизатор, снижая психическое и физиологическое перенапряжение. Синий цвет помогает регулировать допустимый уровень напряжения (действие Эго, старающегося найти компромиссный вариант в борьбе Ид и Супер-Эго), не давая проснуться сновидящему от страха (защитная функция сновидения), справиться со страшным сюжетом до конца, тем самым проработать внутриличностный конфликт (адаптивная функция сновидения) и снизить риск развития невротического состояния.

За счёт того, что в состоянии сна наша психика не перестаёт трудиться, происходит восстановление равновесия в нашем организме и психологическом состоянии.

Жёлтый цвет является активным, бодрящим, тонизирующим на физиологически оптимальном уровне. Наименее утомляющий, жёлтый цвет стимулирует зрение и нервную деятельность, активизирует двигательные центры, вызывает радостное настроение, аккумулирует энергию мышц, стимулирует интеллектуальные способности. Жёлтый цвет создаёт иллюзию солнечного освещения. В сновидениях жёлтый связан с мыслительными процессами, стимулирует линейное логическое мышление и деятельность левой половины головного мозга. Жёлтый цвет способен заметно ослабить напряжение в солнечном сплетении [3; 12].

Розовый цвет можно рассматривать как сочетание красного и белого. Красный цвет возбуждающий, согревающий, активный, энергичный, проникающий, тепловой, активизирует все функции организма. Белый цвет холодный, чистый, спокойный цвет. Розовый цвет оказывает на организм действие красного цвета, но в более мягкой, более физиологически оптимальной форме. Розовый цвет заряжает лёгкостью, счастьем и нежностью. Розовый цвет означает романтичность, доброту, любовь, нежность. Чем он бледнее, тем нежнее выражение любви. Вызывает чувство комфорта, успокаивает, избавляет от навязчивых мыслей, ему свойственна чрезмерная чувствительность. Этот цвет преимущественно оказывает влияние на обоняние [3].

Голубой цвет успокаивает, вызывает ослабление и замедление жизненных процессов, является пассивным цветом, снижает мускульное напряжение и кровяное давление, урежает пульс и замедляет ритм дыхания. Под его действием снижается активность и эмоциональное напряжение, даёт почувствовать ощущение прохлады. Голубой цвет в сновидении помогает достичь внутреннего покоя и душевного равновесия. Он даёт почувствовать вдохновение, творчество, духовное понимание, веру и преданность; ускоряет течение времени и пробуждает воспоминания прошлого. Голубой цвет источает беспечность, надежду, это цвет «спокойной эмоциональности», даёт возможность быть вне границ общества, расширяет пространство. Это цвет мечтаний и грёз, цвет мира и согласия [3; 12].

Зелёный цвет является самым привычным для глаза, нейтральным, мягким, физиологически оптимальным, снижает кровяное давление и расширяет капилляры, успокаивает. Зелёный цвет ослабляет возбуждение слухового центра, ослабляет, освежает и компенсирует громкость шумов. Он обладает антистрессовым эффектом, снимает нервное напряжение, купирует признаки переутомления, усталости. Его длительное воздействие вызывает устойчивый подъём работоспособности. Жёлто-зелёная палитра становится более мягкой 


\section{Психология и психотехника 3(90) • 2016}

и создаёт хорошее настроение. Во время сновидения этот цвет несёт безопасность. Зелёный цвет благотворно воздействует на глубинные чувства сожаления, помогает научиться получать удовольствие от того, что человек имеет в данный момент, и жить без привязок и стремления обладать. Зелёный - цвет природы, он символизирует бесконечную неисчерпаемую жизненную силу [3; 12].

Оранжевый цвет действует в том же русле, что и красный, но мягче и более физиологично: тонизирует, ускоряет пульс, улучшает пищеварение, вызывает ощущение теплоты, веселья, бодрости, создаёт приятное настроение. Благоприятно влияет на работоспособность, если действие его не длительно. В сновидениях оранжевый цвет означает оптимизм, уверенность, перемены, стремление, энтузиазм и отвагу. Оранжевый цвет препятствует склонности к слепому доверию и вызывает стремление найти партнёрство. В оранжевом больше выражено социальной стабильности [3].

Анализируя воздействие на организм в бодрствующем состоянии жёлтого, розового, голубого, зелёного и оранжевого цвета, можно сделать вывод, что и в приятном сновидении эти цвета создают и поддерживают оптимальное состояние психического и физиологического комфорта, тем самым обеспечивая восстановительную функцию сновидения (позволяет ослабленным или перенапряжённым органам перейти к самовосстановлению или отдыху) и компенсаторную функцию сновидения (работа сно- видения по восстановлению необходимого психического баланса, снятию нервного напряжения).

Таким образом, результаты проведённого исследования свидетельствуют о существующей взаимосвязи эмоциональных состояний (страх, тревога, удовольствие, удовлетворение) и вторичных образов, представленных определённым цветом и участвующих в работе защитной, адаптивной и компенсаторной функций сновидения в детских снах.

В детских сновидениях со страшным сюжетом выражено доминирующими являются: чёрный, красный и синий цвета.

В приятных детских сновидениях наиболее часто появляющимися являются жёлтый, розовый, голубой, зелёный и оранжевый.

Можно предположить, что частое появление в сновидениях чёрного, красного и синего цвета является сигналом о наличии психологической проблемы и начале формирования невротического состояния. По интенсивности и частоте появления этих цветов в сновидениях можно судить о степени выраженности внутриличностного конфликта.

Результаты исследования могут быть использованы в рамках ранней диагностики и профилактики невротических состояний, которые ещё не проявились в виде клинических симптомов заболевания, в бодрствующем состоянии, но уже появляются в сновидных образах в виде представленности определённого цвета.

\section{Список литературы:}

1. Алиева Н.3. Физика цвета и психология зрительного восприятия. М.: Академия, 2008. 208 с.

2. Ананьев Б.Г. Психология чувственного познания: уч. пособие. М.: Изд-во АПН РСФСР, 1960. 486 с.

3. Базыма Б.А. Психология цвета. Теория и практика. СПб.: Речь, 2005. 208 с.

4. Высоков И.Е. Математические методы в психологии: учебник и практикум для академического бакалавриата. М.: Юрайт, 2014. 386 с.

5. Гостев А.А. Психология вторичного образа. М.: Институт психологии РАН, 2007. 512 с.

6. Касаткин В.Н. Теория сновидений. М.: Мол. гвардия, 1983. 436 с.

7. Корабельникова Е.А., Вейн А.М., Голубев В.Л., Крейнес М.Г. Психолингвистическое исследование сновидений детей и подростков с невротическими расстройствами // Журнал неврологии и психиатрии. 1999. № 1. С. 18-21.

8. Миронова Л.Н. Учение о цвете. Минск: Высшая школа, 1993. 463 с.

9. Налчаджян А.А. Ночная жизнь Личность в своих сновидениях. СПб.: Питер, 2004. 443 с.

10. Ротенберг В.С. Адаптивная функция сна. Причины и проявления её нарушения. М.: Наука, 1982.175 с.

11. Смирнов Т. Психология сновидений. М.: КСП+, 2005. 598 с.

12. Собчик Л.Н. Метод цветовых выборов. Модифицированный восьмицветовой тест Люшера. СПб.: Речь, 2011. 112 с.

13. Фрейд 3. Толкование сновидений. Мн.: Попурри, 2003. 576 с.

14. Фрейд 3. Введение в психоанализ: Лекции. М.: СГУ, 2007. 528 с.

15. Березина Т.Н. Формирование эмоциональной безопасности образовательной среды (психолого-педагогические аспекты) // Современное образование. 2015. № 1. C. 53-68. DOI: 10.7256/2409-8736.2015.1.13912. URL: http://www.enotabene.ru/pp/article_13912.html.

16. Воротилина А.А. Образная регуляция тревожности студентов (анализ тренинга) // Психолог. 2013. № 6. С. 45-65. DOI: 10.7256/2409-8701.2013.6.9434. URL: http://www.e-notabene.ru/psp/article_9434.html.

\section{References (transliterated):}

1. Alieva N.Z. Fizika tsveta i psikhologiya zritel'nogo vospriyatiya. M.: Akademiya, 2008. 208 s. 
2. Anan'ev B.G. Psikhologiya chuvstvennogo poznaniya: uch. posobie. M.: Izd-vo APN RSFSR, 1960. $486 \mathrm{~s}$.

3. Bazyma B.A. Psikhologiya tsveta. Teoriya i praktika. SPb.: Rech', 2005. 208 s.

4. Vysokov I.E. Matematicheskie metody v psikhologii: uchebnik i praktikum dlya akademicheskogo bakalavriata. M.: Yurait, 2014. $386 \mathrm{~s}$

5. Gostev A.A. Psikhologiya vtorichnogo obraza. M.: Institut psikhologii RAN, 2007. 512 s.

6. Kasatkin V.N. Teoriya snovidenii. M.: Mol. gvardiya, 1983. $436 \mathrm{s.}$

7. Korabel'nikova E.A., Vein A.M., Golubev V.L., Kreines M.G. Psikholingvisticheskoe issledovanie snovidenii detei i podrostkov s nevroticheskimi rasstroistvami // Zhurnal nevrologii i psikhiatrii. 1999. № 1. S. 18-21.

8. Mironova L.N. Uchenie o tsvete. Minsk: Vysshaya shkola, 1993. 463 s.

9. Nalchadzhyan A.A. Nochnaya zhizn' Lichnost'v svoikh snovideniyakh. SPb.: Piter, 2004. $443 \mathrm{~s}$.

10. Rotenberg V.S. Adaptivnaya funktsiya sna. Prichiny i proyavleniya ee narusheniya. M.: Nauka, $1982.175 \mathrm{~s}$.

11. Smirnov T. Psikhologiya snovidenii. M.: KSP+, 2005. $598 \mathrm{~s}$.

12. Sobchik L.N. Metod tsvetovykh vyborov. Modifitsirovannyi vos'mitsvetovoi test Lyushera. SPb.: Rech', $2011.112 \mathrm{s.}$

13. Freid Z. Tolkovanie snovidenii. Mn.: Popurri, 2003. 576 s.

14. Freid Z. Vvedenie v psikhoanaliz: Lektsii. M.: SGU, 2007. $528 \mathrm{~s}$.

15. Berezina T.N. Formirovanie emotsional'noi bezopasnosti obrazovatel'noi sredy (psikhologo-pedagogicheskie aspekty) // Sovremennoe obrazovanie. 2015. № 1. S. 53-68. DOI: 10.7256/2409-8736.2015.1.13912. URL: http://www.e-notabene.ru/ pp/article_13912.html.

16. Vorotilina A.A. Obraznaya regulyatsiya trevozhnosti studentov(analiz treninga) // Psikholog. 2013. № 6. S. 45-65. DOI: 10.7256/2409-8701.2013.6.9434. URL: http://www.e-notabene.ru/psp/article_9434.html. 